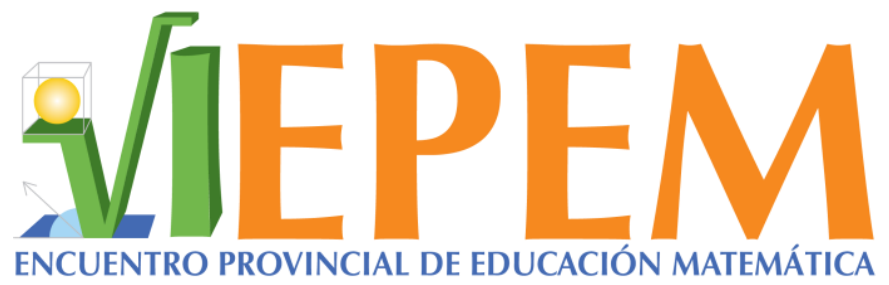

VI Encuentro Provincial de Educación Matemática.

27 al 29 de setiembre, 2017. Puntarenas, Costa Rica.

\title{
El cálculo diferencial e integral en una variable para la argumentación de contenidos de la matemática escolar
}

\author{
Cristian Alfaro-Carvajal \\ cristian.alfaro.carvajal@una.cr \\ Universidad Nacional \\ Costa Rica
}

Jennifer Fonseca-Castro

jennifer.fonseca.castro@una.cr

Universidad Nacional

Costa Rica

\begin{abstract}
Resumen
En los cursos de cálculo de formación inicial de profesores de matemáticas es necesario vincular esta área con los temas de la enseñanza en secundaria. El taller tiene como objetivo la reflexión sobre el uso e importancia del cálculo diferencial e integral en una variable a la luz de algunos contenidos matemáticos de secundaria. Se utilizará la resolución de problemas como estrategia metodológica de trabajo. Se espera que las actividades elaboradas para el taller permitan a los participantes explorar, revisar y ampliar sus conocimientos a partir del estudio de contenidos matemáticos de secundaria.

Palabras clave: Cálculo diferencial e integral; actividades metodológicas para la enseñanza del cálculo; resolución de problemas.
\end{abstract}

\section{Introducción}

Los Programas de Estudio de Matemáticas del Ministerio de Educación Pública (MEP) promueven dentro de su fundamentación, el uso y desarrollo de cinco procesos cognitivos que deberán estar presentes a lo largo de toda actividad de mediación, estos son: (a) razonar y argumentar, (b) plantear y resolver problemas, (c) conectar y establecer relaciones, (d) representar de diversas formas, y (e) comunicar, expresar ideas matemáticas formal y verbalmente. Con lo anterior se busca que los estudiantes puedan realizar procesos matemáticos desde una óptica más analítica, haciendo uso de la justificación y argumentación matemática. Se pretende que durante el desarrollo de las lecciones de

Taller

\footnotetext{
Alfaro-Carvajal, C. y Fonseca-Castro, J. (2017). El cálculo diferencial e integral en una variable para la argumentación de contenidos de la matemática escolar. En Y. Morales-López, M. Picado, R. Gamboa, C. Martínez, M. Castillo y R. Hidalgo (Eds.), Memorias del VI Encuentro Provincial de Educación Matemática, Costa Rica, 2017 (pp. 22-24). Heredia: Universidad Nacional. ISBN: 9789968-9661-5-3. DOI: http://dx.doi.org/10.15359/epem.6.4
} 
matemática los estudiantes experimenten formas típicas del pensamiento matemático, tales como, deducción, inducción, comparación, generalización, justificación, pruebas, entre otros.

\section{Agregan,}

Se busca desarrollar capacidades para permitir la comprensión de lo que es una justificación o prueba en matemática, para desarrollar y discutir argumentaciones matemáticas, para formular y analizar conjeturas matemáticas, para usar fórmulas o métodos matemáticos que permitan la comprensión o desarrollo de informaciones presentes (MEP, 2012, p. 24).

Para lograr lo anterior, es fundamental una formación matemática y pedagógica sólida por parte del docente de matemática a cargo, que le permita establecer relaciones matemáticas entre los temas que enseña y las actividades de mediación que utiliza. Para esto, el docente debe entender la naturaleza de los conceptos matemáticos que quiere enseñar.

El aprendizaje y enseñanza del cálculo diferencial e integral en una variable, en Costa Rica, generalmente se asocia a niveles escolares superiores, o a programas tales como Olimpiadas Matemáticas y Matemática para la Enseñanza Media (MATEM). Sin embargo, muchos de los temas y contenidos de secundaria tienen sus orígenes y pueden fundamentarse con el Cálculo. Por ejemplo: factorización de polinomios, funciones, gráfica de funciones, entre otros.

El objetivo del taller es generar espacios de reflexión sobre la importancia del cálculo diferencial e integral para poder fundamentar algunos conceptos de la matemática de secundaria.

\section{Metodología del taller}

Se utilizará la resolución de problemas como estrategia metodológica para el abordaje de los temas.

El taller está organizado en dos sesiones de trabajo de dos horas. En dichas sesiones, los participantes trabajarán en grupos una lista de actividades que les permitirán explorar, recordar y revisar algunos de los conceptos fundamentales del cálculo diferencial e integral a partir de algunos contenidos de los Programas de Estudio de Matemáticas del MEP. Al final de cada sesión de trabajo grupal, se hará una plenaria para compartir los principales resultados encontrados.

Las actividades han sido diseñadas con el objetivo de que los participantes, a partir de contenidos matemáticos de secundaria, se cuestionen sobre algunas ideas y procedimientos que para entenderlos y justificarlos son útiles algunos contenidos del cálculo. 


\section{Resultados esperados}

Se espera que las actividades elaboradas para el taller permitan a los participantes, la reflexión y revisión de algunos conceptos del cálculo y sus usos en la enseñanza de la matemática a nivel de secundaria.

Además, se espera que los participantes revisen y expandan sus conocimientos sobre el cálculo diferencial e integral, de manera que solidifiquen sus bases matemáticas; y esto se vea reflejado en su práctica docente.

Por último, a partir de la retroalimentación de los participantes, se revisarán y, de ser necesario, se mejorarán las actividades elaboradas para este taller con el objetivo de utilizarlas en la enseñanza y aprendizaje del cálculo diferencial e integral en una variable en la formación inicial de futuros docentes de matemática cursos relacionados.

\section{Referencias}

Ministerio de Educación Pública. (2012). Programas de estudio de matemáticas I, II y III ciclos de la educación general básica y ciclo diversificado. San José, Costa Rica.

\section{(c) $($ ) $\odot \odot$ \\ Esta obra está bajo una licencia de Creative Commons Reconocimiento-NoComercial- SinObraDerivada 4.0 Internacional.}

